\title{
Capacitação de Gestor Cultural: uma Realidade em EAD no Exército Brasileiro
}

\section{Jéssica Tarine Moitinho de Lima1* Ludmila Leite Madeira da Costa Fernanda Cristina Nunes Pontes Marques $^{3}$}

1 Universidade Federal do Pará - Rua Augusto Corrêa, 01 - Guamá, Belém PA, Brasil*j.tarine.lima@gmail.com

2Universidade Federal do Estado do Rio de Janeiro - Av. Pasteur, 458 - Urca Rio de Janeiro, RJ. Brasil.

${ }^{3}$ Exército Brasileiro

\section{Resumo}

Este artigo é uma descrição e análise da experiência do projeto de capacitação Estágio Geral Interdisciplinar de Gestão Cultural, realizado em 2019 pela Diretoria do Patrimônio Histórico e Cultural do Exército, cuja finalidade é de melhor qualificar oficiais, subtenentes e sargentos na gestão de 150 Espaços Culturais do Exército Brasileiro. Em meio às temáticas discutidas aqui estão a apresentação do cenário institucional do EB quanto aos seus Espaços Culturais, o planejamento dos módulos de Museologia e Gestão de Espaços Culturais na modalidade a distância e a descrição dos resultados obtidos na experiência. As práticas aqui descritas deixam espaço para aprimoramento, seja da metodologia utilizada, seja do processo de feedback da capacitação. Podemos concluir que compartilhar este projeto junto à universidade foi fundamental para dar corpo e credibilidade ao projeto. $\mathrm{O}$ sucesso do programa demonstra que é possível uma educação continuada nos conhecimentos que a gestão dos Espaços Culturais demanda. A partir da documentação legal, a experiência é explicitada desde a implementação até os resultados finais de conclusão do estágio pelos militares participantes, demonstrando a concretização dos objetivos propostos, avanços em prol da valorização e preservação do patrimônio militar do Exército Brasileiro.

Palavras-chave: Educação a distância. Museologia. Gestão patrimonial. patrimônio. Exército Brasileiro.

\section{(c) (i)}

Recebido 03/11/2021

Aceito 21/02/2022

Publicado 22/02/2022

\section{COMO CITAR ESTE ARTIGO}

ABNT: LIMA, J. T. M.; COSTA, L. L. M.; MARQUES, F. C. N. P. Capacitação de Gestor Cultural: uma Realidade em EAD no Exército Brasileiro. EaD em Foco, v. 12, n. 1, e1655, 2022. doi: https://doi. org/10.18264/eadf.v12i1.1655 


\section{Cultural Manager Instruction: a Reality in Distance Learning in the Brazilian Army}

\section{Abstract}

This article is a description and analysis of the experience of the 'Interdisciplinary General Management of Cultural Administration' training project, conducted in 2019 by the Diretoria do Patrimônio Histórico e Cultural do Exército, whose purpose is to better qualify officers, warrant officers and sergeants in the management of 150 Cultural Spaces of the Brazilian Army. Amid the themes discussed here are: the presentation of the institutional scenario of the $E B$ regarding its Cultural Spaces; the planning of modules for Museology and Management of Cultural Spaces in distance learning mode; and the description of the results obtained in the experiment. The practices here analyzed, allow space to improve in the training, both methodology or the feedback process. It can be concluded that sharing this project with the university was fundamental to give credibility and content to itself. Its success demonstrates a possibility in the continuity education when talking about knowledge in management of Cultural Spaces. From the legal documentation, the experience is explained from the implementation to the final results of the internship conclusion by the participating military personnel, demonstrating the achievement of the proposed objectives, advances in favor of the valorization and preservation of the military heritage of the Brazilian Army.

Keywords: Distance education. Museology. Heritage management. Heritage. Brazilian Army.

\section{Introdução}

O Exército Brasileiro (EB) é detentor de um diversificado patrimônio cultural material e imaterial, produto de uma memória coletiva que é o suporte essencial da identidade da instituição. Todo esse acervo encontra-se sob a guarda dos Espaços Culturais do EB, localizados nas diversas organizações militares vinculadas tecnicamente à Diretoria do Patrimônio Histórico e Cultural do Exército (DPHCEx). Esta, por sua vez, tem por função precípua promover e coordenar o processo de preservação do patrimônio cultural militar, visando fortalecer, salvaguardar a memória e vivificar a história da Força Terrestre.

O conjunto de esforços em prol do patrimônio militar no Exército Brasileiro se estabelece por meio do Sistema Cultural do Exército (SCEx), que tem por finalidades a coordenação na consecução dos objetivos culturais e o estabelecimento de um canal técnico entre os diversos escalões, racionalizando o fluxo de informações de interesse da área cultural. Ele atua alinhado com o Sistema de Comunicação Social e com o Sistema de Ensino, prioritariamente no sentido de desenvolver os valores éticos e morais, aprimorar a vocação militar, promover o culto aos valores e tradições e de acentuar o compromisso do Exército com a Nação Brasileira pelo cumprimento de sua destinação constitucional. Integram o SCEx as $5^{\text {a }} / 7^{a}$ Seções dos Comandos Militares de Área, dos Grandes Comandos e das Grandes Unidades, na figura do Assessor Cultural, e as Seções ou Elementos de Comunicação Social de todas as Organizações Militares na figura do Gestor Cultural que atua nos Espaços Culturais do Exército.

O Exército Brasileiro possui hoje 150 Espaços Culturais, de diversas tipologias, homologados pelo Comandante do Exército, espalhados por todo o território nacional. Estes Espaços Culturais assim como seus 
gestores são considerados pela Força guardiões do patrimônio histórico-cultural militar. A mão de obra mais comum nestes espaços são os militares sem formação especializada nos campos da Museologia e/ou Patrimônio, e atuam sob orientação da DPHCEx nos processos de gestão e preservação de seus acervos.

A dinâmica de gerência desenvolvida nestes Espaços Culturais torna necessário que os atores nela envolvidos estejam qualificados para a tarefa. Neste sentido, torna-se iminente a capacitação dos gestores culturais para que os mesmos tenham conhecimento dos processos e práticas museológicas aplicáveis em qualquer Espaço Cultural de preservação e comunicação de patrimônios.

A Lei n 7.287, de 18 de dezembro de 1984, que regulamenta a profissão de museólogo, em seu artigo $3^{\circ}$ dispõe sobre as atribuições deste profissional e, dentre elas, está no inciso I: "ensinar a matéria Museologia, nos seus diversos conteúdos, em todos os graus e níveis, obedecidas as prescrições legais" (BRASIL, 1984). Desta maneira e, de acordo com a matéria legal, verificamos que parte das atribuições do museólogo é, também, colaborar na capacitação daqueles que trabalham diretamente com acervos museológicos.

Para sanar a demanda por capacitação em atividades de preservação e salvaguarda dos patrimônios do Exército, foi criado o programa de Estágio Geral Interdisciplinar de Gestão Cultural do Exército Brasileiro, objetivando ensinar, dentre muitas disciplinas, conteúdos de Museologia aos oficiais, subtenentes e sargentos que exercem cargo de responsabilidade administrativa nos 142 Espaços Culturais da Força Terrestre brasileira. Para execução do programa, foram construídas parcerias com algumas universidades federais, tais como a Universidade Federal Fluminense (UFF), para as disciplinas de Turismo e Marketing, e a Universidade Federal do Estado do Rio de Janeiro (UNIRIO) para as disciplinas de Museologia, Gestão de Espaços Culturais, dentre outras. Neste artigo, iremos apenas adentrar as especificidades da capacitação em Museologia e Gestão de Espaços Culturais. As tenentes museólogas temporárias da Diretoria do Patrimônio Histórico e Cultural do Exército (DPHCEx), junto à professora da Escola de Museologia da UNIRIO foram as responsáveis pela construção do programa, conteúdo e Ambiente Virtual de Aprendizagem (AVA) para as disciplinas de Museologia e Gestão de Espaços Culturais, materializando o trabalho conjunto entre conhecimentos técnicos internos e externos à instituição Exército Brasileiro.

O Estágio Geral Interdisciplinar de Gestão Cultural (EGIGC), criado pela Portaria n053-EME, de 11 de março de 2019, e regulado pela Portaria n 052-EME, de 11 de março de 2019, alterado pela Portaria $n^{\circ}$ 156-EME, de 8 de Julho de 2020 (EME, 2019a, 2019b, 2020), foi a solução adotada para a problemática da falta de museólogos nos Espaços Culturais da Força, qualificando adequadamente os oficiais, subtenentes e sargentos do Exército Brasileiro, para administrar os Espaços Culturais com objetivos de salvaguardar o patrimônio militar. A documentação legal supracitada marca o início de um processo de difusão dos conhecimentos museológico e do patrimônio, dentre outros, como veremos mais adiante.

O EGIGC, como o próprio nome implica, se concretiza por meio da interdisciplinaridade característica da realidade dos Espaços Culturais e das práticas museológicas que tais realidades exigem. Fazem parte do corpo estrutural do EGIGC os seguintes módulos: Museologia, Gestão de Espaços Culturais, Turismo, Gestão de Marketing e Mídias Sociais, Arquitetura, Projetos Culturais, História, Direito, Metodologia da Pesquisa e Projeto de Conclusão de Estágio, sendo atribuída a importância ao diálogo interdisciplinar para uma prática museológica que objetiva a inclusão, democratização e qualidade das ações dos Espaços Culturais para a sociedade.

O patrimônio cultural é o referencial para o desenvolvimento das ações museológicas. Os processos museais pertinentes a um Espaço Cultural contribuem, de modo efetivo, para a ampliação do conceito de patrimônio na medida em que o conceitua como a relação do homem com o meio. Desta forma, as ações museológicas têm como referencial o patrimônio global, e não apenas os bens culturais (SANTOS, 2003).

Este artigo trata da descrição e análise da experiência do primeiro ano de estágio dos módulos de Museologia e Gestão de Espaços Culturais, conteúdos referentes à especialidade das autoras e cujo progra- 
ma e acompanhamento das ações foram por elas desenvolvidos. Apresenta como foi elaborado e executado o programa de Estágio Geral Interdisciplinar de Gestão Cultural do Exército Brasileiro, sob o modelo $E A D$, e os resultados obtidos a partir da experiência para o grupo social de militares, agentes internos da Força e suas relações com o patrimônio militar.

\section{A gestão do patrimônio}

No Brasil, a Constituição Federal (BRASIL, 1988) define patrimônio como "bens de natureza material e imaterial portadores de referência à identidade, à ação e à memória dos diferentes grupos formadores da sociedade [...]". Esta definição parte da atribuição de valores intrínsecos ao conceito que permite diferenciar um objeto dos demais, de forma que, um bem cujos valores foram reconhecidos em território nacional, diferenciando-o dos demais, é considerado patrimônio nacional. É essa diferenciação que evoca ao bem a necessidade de preservação e perpetuação destes valores (PONCIANO et al., 2015).

O patrimônio militar e nacional sob salvaguarda dos Espaços Culturais militares e consequentemente de seus gestores pode ser caracterizado de diversas maneiras. Apresenta-se então, o conceito de Patrimônio Militar, segundo o Plano Básico de Cultura do Exército Brasileiro (2019-2020):

Toda manifestação concreta dos recursos utilizados do preparo militar para guerra, assim como artefatos, construções, obras de arte e objetos produzidos artesanalmente ou industrialmente que expressem a vida e as relações na caserna, contribuindo para conservação da memória e da história do Exército Brasileiro (PLANO BÁSICO DE CULTURA DO EXÉRCITO BRASILEIRO, 2019-2020).

O processo de valoração dos bens culturais está intrínseco ao reconhecimento de sua importância e função como bem cultural. Sobre o papel do objeto na sociedade, Dohmann (2010) afirma:

O objeto reflete simbolismo que envolve universos mentais, em atribuições de sentidos caracterizados por fluxos imagéticos de diferentes graus de subjetividade, desde simples experiências de "estar no mundo" até a aura criada pelo próprio artefato, em sua condição de ícone, na tarefa de comunicar experiências culturais (DOHMANN, 2010, p.72).

Esse bem é dotado de valores simbólicos intrínsecos à sua existência e sua relação com a sociedade. Entretanto, um objeto sozinho ou um conjunto de objetos podem ser interpretados de diversas formas. O reconhecimento e a valoração desses bens culturais são vitais para a preservação dos mesmos, como despertar a conscientização da necessária valoração e consequente valorização ${ }^{1}$ dos bens culturais que permeiam seus Espaços Culturais é um desafio cotidiano do Exército Brasileiro.

Os Espaços Culturais configuram-se como agentes de integração entre os indivíduos e as mais diversas narrativas culturais. São lugares de definição e de fortalecimento das identidades culturais, assim como de formação e produção de conhecimento (RAFAEL, 2017). Os Espaços Culturais do EB são, por natureza, depositários e expositores de um acervo de interesse histórico militar, educativo e elucidativo de uma

1 Dois termos ressaltam quando se analisa a atribuição de valores e sua atuação sobre a vida de um bem cultural e científico. São eles: a valoração e a valorização. A valoração, cujo significado compreende a apreciação e atribuição de valor a um objeto. A valorização encerra o significado de aumento de um valor pré-existente, incorporando importância ou qualidade ao bem. Neste sentido, a valoração deve ser pensada como um passo inicial e valorização como um passo após a consolidação de políticas de preservação e curadoria. 
identidade e que expressa, não só a permanência da Força ao longo da história nacional, assim como a essência do espírito de corpo que, mais do que em qualquer outra instituição, marca de forma indelével as solidariedades horizontais e, sobretudo verticais entre os seus elementos, fazendo desse um fator de dependência, multiplicidade e eficiência. O Exército Brasileiro reconhece oito tipologias de Espaço Cultural:

(I) Casa Histórica: é um bem edificado, de interesse da cultura militar, onde nasceu ou morou algum vulto importante para a História Militar, que abrigou algum Órgão da sua estrutura organizacional ou onde ocorreu algum acontecimento de destaque ligado ao passado da Instituição; (II) Memorial: é o espaço destinado à reverência de um fato ou personagem histórico, composto de acervo, objetos (bustos, estátuas, dentre outros) ou documentos relativos a uma pessoa, cidade ou época que caracterize uma cultura militar; (III) Monumento: obra ou construção que se destina a transmitir à posteridade, à memória e recordação de fato ou pessoas notáveis na História Militar; (IV) Museu Militar: é toda instalação permanente, aberta ao público, possuidora de um corpo técnico ligado à área de conhecimento da museologia, criada para coletar, preservar, pesquisar e expor, para fins de estudo, educação e entretenimento, objetos de interesse da cultura militar; (V) Parque Histórico: é um complexo de Espaços Culturais militares articulados entre si num determinado espaço geográfico, com objetivo de preservar o local em que se encontram; (VI) Sala de Exposição: é um local onde estão expostos objetos de interesse da cultura militar, com a finalidade de preservar a história de uma Organização Militar (OM) ou do Exército Brasileiro relacionada com a História do Brasil, objetivando a preservação e a divulgação dos valores, das crenças e das tradições militares; (VII) Sala de Troféus: é um espaço destinado à exposição de troféus que tenham valor histórico ou tradição para a OM ou para o Exército Brasileiro; e (VIII) Sítio Histórico: local onde ocorreu algum fato ligado à história da OM ou do Exército (ESTADO- MAIOR DO EXÉRCITO, 2013).

A variedade tipológica dos espaços culturais, além de não ter mão de obra especializada dentro da Força Terrestre, possui diferentes problemáticas ligadas às realidades específicas destes locais. Padronizar as práticas de preservação e gestão, assim como divulgar estes acervos se torna necessidade e mister para o EB.

A atenção às políticas culturais, especialmente no Brasil, é recente. Somente a partir dos anos 1980, o conjunto de ações voltadas para esta temática registraram os desafios complexos destas práticas (RAFAEL, 2017; RUBIM, 2007). A política cultural pode ser compreendida como um conjunto de princípios, práticas administrativas e orçamentárias e os procedimentos que fornecem uma base para a ação cultural do Estado (Rafael, 2017). Com um panorama, Santos (2003) descreve o campo da museologia:

Nos últimos 30 anos, produzimos e provocamos grandes transformações no campo da Museologia. Considerando que o fazer museológico é o resultado das relações humanas, em cada momento histórico, em relação com as demais práticas sociais globais, podemos afirmar que a Museologia, em transformação, é resultado de um mundo em transformação (SANTOS, 2003, p.2).

A Declaração de Caracas (1992) descreve como um dos desafios dos museus da América Latina a capacitação de seus agentes: 
O Museu da América Latina deve responder aos desafios que Ihe são impostos hoje pelo meio social no qual está inserido, pela comunidade a que pertence e pelo público que se comunica. Para enfrentá-los é necessário: 1) Desenvolver sua qualidade, como espaço de relação entre os indivíduos e seu patrimônio, onde se propicia o reconhecimento coletivo e se estimula a consciência crítica.

2) Abrir caminhos de relação entre o Museu e os dirigentes políticos para que estes compreendam sua ação e se comprometam com ela. 3) Desenvolver a especificidade da linguagem museológica como mensagem aberta, democrática e participativa. 4) Refletir as diferentes linguagens culturais com base em códigos comuns, acessíveis e reconhecíveis pela maioria. 5) Revisar o conceito tradicional de patrimônio museal de uma nova perspectiva, onde o entorno seja ponto de partida e de referência obrigatório. 6) Adotar o inventário como instrumento básico para a gestão do patrimônio. 7) Lutar pela valorização social do funcionário de museus em termos de reconhecimento, estabilidade e remuneração. 8) Priorizar na instituição museológica a formação profissional integral do funcionário de museus. 9) Estabelecer mecanismos de administração e captação de recursos como base para uma gerência eficaz (ICOM, 1992, p.262-263, grifo nosso).

O oitavo item denota a importância da instrumentalização, teórica e técnica, do agente do espaço cultural para o atendimento de forma exitosa das atividades inerentes a uma instituição museológica. Rafael (2017) ressalta ainda a reflexão sobre o papel dos gestores dessas instituições, buscando a criação de condições propícias para que todos os profissionais atuantes nestes espaços, além de participar de oportunidades de qualificação, desenvolvam e pratiquem os ensinamentos abordados nos cursos e oficinas.

A profissionalização do agente que trabalha em museus deve ser uma prioridade, pois contribui para o desenvolvimento integral da comunidade. A capacitação deve desempenhar a tarefa interdisciplinar própria do espaço museológico, e conceder os elementos indispensáveis para exercer uma liderança social, uma gerência eficiente e uma comunicação adequada (BRUNO, 2010). Rafael (2017) acrescenta ainda:

As variáveis territoriais e políticas compõem as experiências e formatam diferentes lógicas que motivaram ou desmotivaram a frequência aos módulos, o que pode ser descrito pelos diferenciais de assiduidade de cada oficina e a relativa adesão dos museus a todos os módulos executados (RAFAEL, 2017).

A iniciativa de promover programas de capacitação que envolvem a Museologia é uma prerrogativa do Estatuto de Museus (BRASIL, 2009), em seu artigo 58, inciso IV, que atribui ao Sistema Brasileiro de Museus a promoção e:

o desenvolvimento das ações voltadas para as áreas de aquisição de bens, capacitação de recursos humanos, documentação, pesquisa, conservação, restauração, comunicação e difusão entre os órgãos e entidades públicas, entidades privadas e unidades museológicas que integrem o Sistema (BRASIL, 2009, ênfase nossa).

Atrelado a esta legislação, o programa Saber Museu, do Instituto Brasileiro de Museus (IBRAM), lançado em dezembro de 2019, é um exemplo de capacitação de recursos humanos. Este programa do IBRAM é 
uma iniciativa voltada para a capacitação de profissionais que atuam em museus e instituições afins, visando à difusão do conhecimento e ao aprimoramento da gestão do campo museal.

Desde 2003, o reconhecimento da necessidade de formação e capacitação para atuação em museus vem se desenvolvendo no âmbito da Política Nacional de Museus (PNM), que resultou na criação do IBRAM em 2009, e que hoje apresenta cursos como o citado no parágrafo acima. Apresentado como eixo dessa política, a "formação e capacitação de recursos humanos" foi o primeiro eixo da PNM a ser aplicado dentre as ações que previam o desenvolvimento do campo museal brasileiro (TOLENTINO, 2009). Naquele momento, foram realizadas oficinas presenciais por todo o país. A modalidade EAD ainda não era uma realidade amplamente difundida e/ou estruturada. Atualmente e, diante da situação mais recente vivida na pandemia pelo COVID-19, a modalidade EAD se faz não apenas como uma opção, mas uma realidade presente e necessária. Mesmo antes do atual cenário, o Exército Brasileiro concebeu seu programa de capacitação em Museologia na modalidade EAD que, como veremos adiante, melhor atende o público de gestores da Força e sua demanda interna.

Outro importante agente a ser considerado é o Sistema Brasileiro de Museus (SBM), criado por meio do Decreto $n^{\circ}$ 5.264, de 5 de novembro de 2004, com a seguinte finalidade: promover a interação entre os museus brasileiros; o registro e a disseminação dos conhecimentos do campo museológico; a gestão integrada e o desenvolvimento das instituições, acervos e processos museológicos; e o desenvolvimento de ações de capacitação, documentação, pesquisa, conservação e difusão entre as unidades museológicas que integram o Sistema (RAFAEL, 2017). Assim como a PNM, o SBM prevê a capacitação dos profissionais que trabalham em museus e espaços culturais como uma ação fundamental para o desenvolvimento museal.

A formação de recurso humano voltado especificamente para as demandas da cultura é uma das maneiras eficazes de incluí-la na agenda das políticas locais. Segundo o relatório da Pesquisa de Informações Básicas Municipais (Munic) do Instituto Brasileiro de Geografia (IBGE), realizada em 2006, a implantação deste tipo de programa é considerada um dos desafios para que o setor se posicione de forma contundente no conjunto das políticas públicas nacionais culturais (INSTITUTO BRASILEIRO DE GEOGRAFIA E ESTATÍSTICA, 2007; RAFAEL, 2017).

Destaca-se aqui a atuação precursora de capacitação e formação no campo museológico do Sistema Estadual de Museus Catarinenses (SEM/SC), iniciada em 1987. A atuação do SEM/SC voltou-se para diversos eixos; ressaltamos aqui a capacitação e formação de agentes de museus e espaços culturais. As dezenas de oficinas de capacitação, de pequeno e longo prazo, oferecidas pelo sistema desde sua implementação, reforçam os benefícios desse tipo de prática no campo. Também era o intuito do programa de capacitação que ele propiciasse aos agentes um conhecimento maior sobre a Museologia, os museus e a função social desse equipamento cultural na contemporaneidade (RAFAEL, 2017).

\section{Um projeto para todo o Brasil}

Compreendendo o panorama nacional e as necessidades imperativas de capacitação de mão de obra, capaz de salvaguardar o patrimônio militar, concebe-se o Estágio Geral Interdisciplinar de Gestão Cultural (EGIGC), com a seguinte finalidade:

Parágrafo único. O Estágio Geral Interdisciplinar de Gestão Cultural tem como objetivo preparar militares para o desempenho da tarefa de gerenciar atividades e propostas voltadas para bens e ações culturais, como: controle de acervos, planejamento de exposições e eventos, manutenção de patrimônio, desenvolvimento turístico militar nos Espaços Culturais e propagação do Plano Cultural do Exército, de acordo com a 
jurisdição e as políticas patrimoniais e culturais, em alinhamento com as assessorias dos Centros Regionais de Cultura Militar (ESTADO-MAIOR DO EXÉRCITO, 2019b)

O EGIGC, como descrito em sua legislação de criação, é desenvolvido por meio da plataforma de Ensino a Distância em Ambiente Virtual de Aprendizagem (plataforma moodle), disponibilizado no Portal da Educação do Exército Brasileiro. A escolha pelo ambiente virtual se deu a fim de alcançar, de forma equivalente, o maior número de militares, que atuam como gestores dos Espaços Culturais espalhados por todo o território nacional. Santos (2003) descreve os objetivos principais de um curso de capacitação:

Cursos de Formação e Capacitação, na Área da Museologia, deverão assumir o compromisso com o desempenho qualitativo, preparando profissionais que sejam capazes de produzir conhecimento, buscando, também, a interseção criativa de contribuições conceituais e analíticas de outras disciplinas, contribuindo com a renovação dos processos museais, reconhecendo as especificidades dos diferentes contextos, adequando os procedimentos metodológicos e técnicos às diferentes realidades, com a abertura necessária para a devida avaliação e reflexão crítica (SANTOS, 2003, p.11).

A Museologia e a Educação podem ser consideradas histórico-socialmente condicionadas, assumindo, em cada período histórico, características que são resultado das ações do homem no mundo (SANTOS, 2003).

Vale ressaltar que os Espaços Culturais do Exército Brasileiro são parte integrante das dinâmicas dos quartéis, e estes não são restritos a áreas de alto índice populacional; muitos locais apresentam situação inadequada para a dinâmica de aula presencial e restrições de acesso à internet. Locais com este perfil foram contabilizados como foco e inseridos nesta solução. Um curso EAD com ferramentas digitais e atividades assíncronas possibilita que o cursando planeje seus horários de acesso à plataforma e aos conteúdos para realização das atividades, de acordo com sua disponibilidade de acesso e dentro ou fora do período de prestação dos serviços militares.

O EGIGC tem a duração máxima de 6 meses, e os estagiários participantes são avaliados por meio de três aferições (formativa, somativa e final) ao longo dos módulos, devendo os mesmos apresentarem um trabalho de conclusão do estágio a fim de obterem o certificado. O público principal do EGIGC são os gestores dos Espaços Culturais do Exército Brasileiro, sendo possível capacitar até 35 militares por turma, durante anos intercalados.

O curso teve três instâncias de coordenação, no ano de 2019, como coordenador geral, o Coronel Marcelo de Mello Ribeiro (Chefe da Seção de Patrimônio e Planejamento Cultural da DPHCEx), o coordenador acadêmico Professor Doutor Paulo André Leira Parente (Escola de História - UNIRIO) e a coordenadora pedagógica Professora Doutora Patrícia Regina Corrêa Wanzeller (Historiadora - Adjunto da Seção de Patrimônio e Planejamento Cultural da DPHCEx), além do corpo de tutores (Fernanda Cristina Nunes Pontes Marques, Jéssica Tarine Moitinho de Lima, Amanda Maia de Amorim, Lydia Norina Macharette Frangella, Patrícia Regina Corrêa Wanzeller e Tatiana Cadilhe Câmara Queiroz) para cada módulo e do corpo de assistência de ensino a distância do Centro de Educação a Distância do Exército (CEADEx).

O EGIGC possui carga horária total de 160h, sendo 40h destinadas ao módulo de Museologia e $20 \mathrm{~h}$ para o módulo de Gestão de Espaços Culturais. Todo o processo de construção da ementa de ambos os módulos foi realizado pela museóloga e professora Ludmila Costa, vinculada ao Departamento de Estudos e Processos Museológicos - DEPM do Centro de Ciências Humanas e Sociais da UNIRIO. 
O módulo de Museologia teve por objetivo a apresentação da definição de termos e conceitos básicos do campo da Museologia e do Patrimônio, por meio dos quais os alunos tiveram contato com os diferentes modelos conceituais do fenômeno social museu, como é entendido conceitualmente a instituição no campo museológico. As relações inter e multidisciplinares da Museologia também foram apresentadas, bem como a compreensão do papel dos museus na sociedade e o reconhecimento de sua função para a preservação dos patrimônios nacionais e, em especial, o militar. Todo o conteúdo conceitual buscou o alinhamento com as práticas desempenhadas em museus e/ou Espaços Culturais: noções básicas dos procedimentos técnicos de preservação e conservação de bens culturais, como documentação em museus, comunicação em museus, política de preservação e segurança, política de aquisição e descarte de coleções, visando adequar às realidades dos Espaços Culturais do EB.

No módulo de Gestão de Espaços Culturais, foram apresentados os principais instrumentos legais vigentes no Brasil e que buscam aperfeiçoar e regular o trabalho e as atividades em museus e Espaços Culturais. O módulo visou dar subsídios mínimos quanto ao uso da principal ferramenta administrativa para gerenciamento de Espaços Culturais sob o ponto de vista da Museologia, o plano museológico.

Para a execução e preparação dos módulos, o processo de gravação das vídeo-aulas (Figura 1) ocorreu em junho de 2019, no CEADEx. O local possui uma estrutura de estúdio profissional para gravação e edição do conteúdo.

O processo de montagem do ambiente em AVA, realizado pelas tutoras do módulo, foi estruturado com base no planejamento da professora conteudista. As diversas atividades propostas, cada uma com seu foco, foram criadas visando à integração do conteúdo para com a realidade do EB, tendo sempre como referência o EC de atuação dos gestores.

Figura 1: Imagens retiradas das vídeoaulas. A. apresentação da professora para o módulo de Museologia. B. recorte da segunda aula do módulo de Gestão de EC sobre plano de gestão.
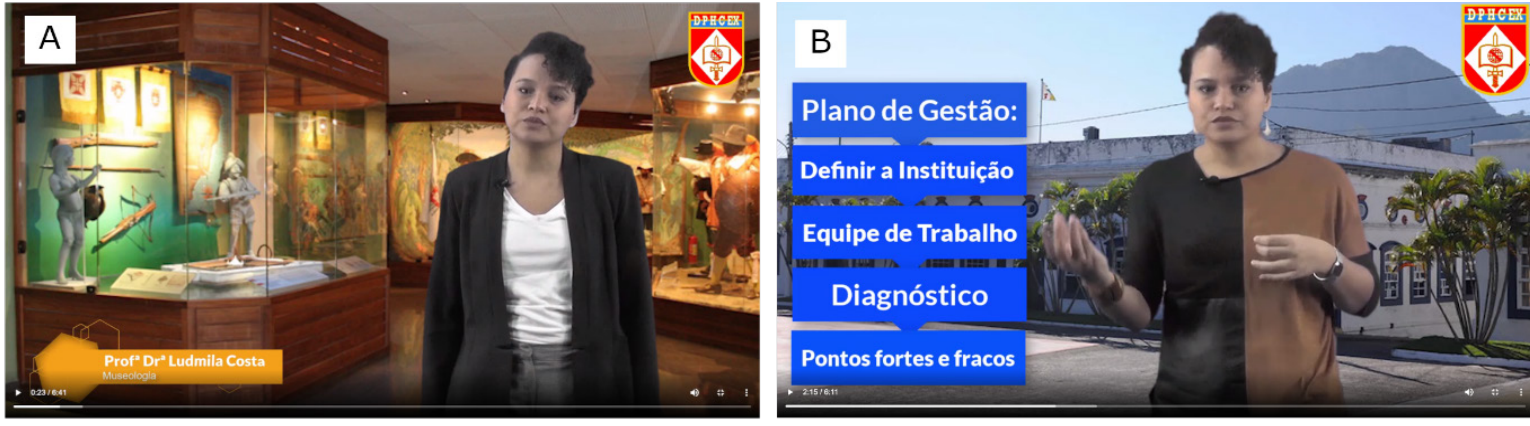

A identidade visual do estágio (Figura 2), como um todo, foi feita por meio da separação do conteúdo proposto em unidades dentro de cada disciplina. Visando manter uma uniformidade no conteúdo proposto, cada unidade possuía, no mínimo, um vídeo introdutório ao tema e uma atividade para correlação da prática vivenciada pelo gestor ao conteúdo estudado. Também foram incluídos, quando pertinentes, a leitura de textos conceituais e a legislação vigente para complementação do aprendizado. 
Figura 2: Imagens da sala de aula do estágio. A. visão parcial do módulo de Gestão de EC, destacando a estrutura em unidades e algumas das tipologias de tarefas utilizadas. B. visão parcial do conteúdo da primeira vídeoaula de Museologia, disponível em H5P.

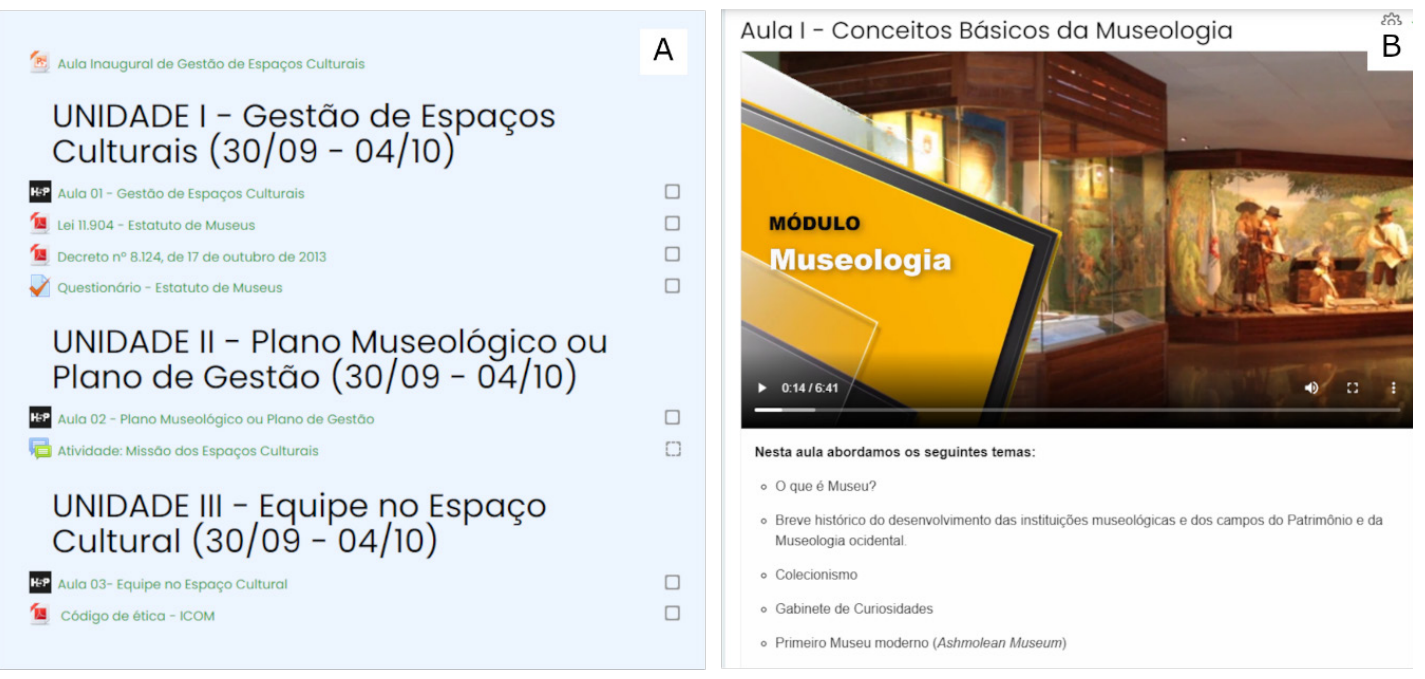

A capacitação dos gestores se concretizou principalmente durante os momentos de tutoria, onde era possível obter o feedback sobre o aprendizado. Ficou claro, então, que o segredo para uma boa comunicação em ambiente virtual estava nas propostas de atividades, compatíveis com a realidade local.

\section{Resultados da primeira turma}

Os preparativos para a primeira turma do EGIGC tomaram maior vulto e atenção no ano de 2018, onde foram feitas as reuniões de alinhamento junto aos professores conteudistas. No ano seguinte, foram realizadas as gravações das vídeoaulas e a montagem do ambiente virtual. Para esta primeira turma, houve um contato inicial por meio da aula inaugural realizada durante o XI Encontro dos Integrantes do Sistema Cultural do Exército, entre julho e agosto de 2019, na cidade do Recife. Nesta oportunidade, todos os inscritos no curso puderam se ambientar com as regras do curso e com as disciplinas, por meio de palestras ministradas pelos professores conteudistas.

A introdução dos conceitos relativos à preservação, valoração e divulgação de acervos ficou clara durante algumas atividades em fórum, que permitem não só a comunicação entre tutor e aluno, mas também entre os próprios alunos. Nessa situação, os alunos demonstram não só entendimento da atividade proposta, como também a compreensão da realidade de outros Espaços Culturais que compartilham da realidade de gerenciamento militar. Tais exemplos fortalecem a visão de gerenciamento e abrem portas para as possibilidades de práticas a serem tomadas como exemplos.

Dentro da proposta para a primeira turma, foram desenvolvidos exercícios que os auxiliassem com as tarefas do cotidiano nos Espaços Culturais. Destaca-se aqui a intitulada "10 atitudes de conservação", onde a proposta era que os gestores levantassem dez ações ligadas ao manuseio e preservação dos acervos, a fim de que pudessem utilizar esse material na capacitação de outros indivíduos que lidam com o acervo. Produtos de qualidade foram produzidos e incorporados às rotinas nos Espaços Culturais militares.

\section{Considerações finais}

A falta de conhecimentos adequados para gerir os Espaços Culturais e museus no Brasil é uma realidade que vem sendo transformada na última década através de programas de formação e capacitação no 
campo museal. O objetivo desses programas circundam a melhoria da gestão e das ações de preservação destes espaços. O modelo de Ensino a Distância-EAD possibilita o alcance a mais agentes sociais que trabalham com o patrimônio. Esta realidade não é diferente no Exército Brasileiro, que conta com o Centro de Educação a Distância do Exército e realiza um programa de capacitação especializado para seus oficiais sem interromper a dinâmica das missões da Força Terrestre, que implicam atividades de quartel.

Diante da realidade e do contraponto entre ter muitos espaços de preservação da memória e da história do Exército, mas poucos profissionais especializados na disciplina competente para geri-los (a Museologia), a instituição elaborou o programa de Estágio Geral Interdisciplinar de Gestão Cultural, a fim de promover a capacitação básica de oficiais, subtenentes e sargentos que estão à frente da organização e gestão dos Espaços Culturais do EB.

Detentor de mais de cem Espaços Culturais de diferentes tipologias, dentre elas museus, monumentos, memoriais, e outras definidas pela própria instituição militar e que atendem à sua política de salvaguarda do patrimônio militar, o Exército Brasileiro tem buscado capacitar seus gestores, promovendo a difusão de conhecimento especializado e valoração de seus acervos.

Tendo iniciado a primeira turma em 2019 e formando 15 gestores em 2020, o Estágio Geral Interdisciplinar de Gestão Cultural é um caso bem sucedido em meio a um conjunto de práticas de aprimoração da gestão do patrimônio cultural do Exército Brasileiro. O sucesso do programa demonstra que é possível uma educação continuada nos conhecimentos que a gestão dos Espaços Culturais demanda. A modalidade do Ensino a Distância é outro fator que assegura o alcance almejado pela Força para atender a todo o território brasileiro onde existem Espaços Culturais, museus e monumentos representativos para a história e memória militar, ou seja, onde é preciso preservar o patrimônio do Exército Brasileiro.

A capacitação destes agentes permite a valorização e reconhecimento do trabalho do museólogo dentro e fora da Força Terrestre. É importante ressaltar que a capacitação oferecida nos módulos de Museologia e Gestão de Espaços Culturais, cujos conteúdos abordam práticas museológicas a serem empregadas nos espaços que preservam e salvaguardam o patrimônio militar do EB, não torna os oficiais, subtenentes e sargentos, gestores destes espaços, profissionais especializados nestas práticas. É preciso contínuo aporte e acompanhamento do corpo técnico das DPHCEx, estas sim, profissionais museólogas formadas e especializadas nos conceitos e práticas que validam as ações de preservação e gestão dos Espaços Culturais, que devem continuar atuando nas especificidades da área.

Lembremos que os militares responsáveis pelos Espaços Culturais têm, antes de tudo, atribuições da vida militar a serem exercidas em seus lugares de trabalho que se distanciam das atividades nos EC e, por este motivo, a conscientização sobre as ações específicas de salvaguarda do patrimônio a serem implementadas nestes locais foi o principal resultado do EGIGC para os militares que concluíram o estágio. Os participantes reconheceram mudança na percepção sobre os espaços e patrimônios de que cuidavam. O estágio promoveu o autorreconhecimento do patrimônio militar para a própria categoria.

Atualmente, outra turma está em desenvolvimento com a expectativa de formação de mais 26 gestores culturais. Após a avaliação do programa pela equipe de militares e civis participantes, pensa-se na inclusão de novos conteúdos e propostas que se adéquem à realidade de gestão do patrimônio cultural militar.

Conhecendo e compreendendo melhor as especificidades dos lugares em que trabalham, os oficiais, subtenentes e sargentos estão mais capacitados a pensar a valorização dos bens que comportam as organizações militares nas quais atuam e a solicitar colaboração técnica, quando necessário, das museólogas da Força Terrestre, entendendo as funções e objetivos do campo de atuação delas. O trabalho de conscientização destes gestores é fundamental para que, quando possível, o trabalho do museólogo ocorra em sincronia com as expectativas dos comandantes. 
Não basta capacitar os agentes técnicos de museus, mas também é preciso uma ação mais efetiva de articulação e sensibilização junto aos comandantes de organizações militares sobre o potencial dos museus como espaços da construção de conhecimento, tomada de consciência e, por fim, de transformação social. Além disso, cabe a orientação quanto às responsabilidades, as quais a legislação brasileira compromete esses gestores, no que diz respeito à preservação e difusão do patrimônio cultural, especialmente à Lei Federal 11.904/2009 e ao Decreto 8.124/2013 (BRASIL, 2009, 2013).

\section{Agradecimentos}

Ao Exército Brasileiro, que possibilitou a construção deste artigo por meio da disponibilização de seus profissionais e dados do estágio. A todos os profissionais e militares que atuaram direta ou indiretamente no EGIGC.

\section{Referências}

BRASIL. Constituição da República Federativa do Brasil de 1988. Emenda constitucional n. 91, de 2016. Disponível em: http://www.planalto.gov.br/ccivil_03/constituicao/constituicao.htm. Acesso 14 ago. 2020.

BRASIL. Decreto $\mathbf{n}^{\circ} \mathbf{8 . 1 2 4}$, de 17 de outubro de 2013. Regulamenta dispositivos da Lei $n^{\circ} 11.904$, de 14 de janeiro de 2009, que institui o Estatuto de Museus, e da Lei $n^{\circ}$ 11.906, de 20 de janeiro de 2009, que cria o Instituto Brasileiro de Museus - IBRAM. Disponível em: < http://www.planalto.gov.br/ccivil_03/_Ato2011-2014/2013/Decreto/D8124.htm>. Acesso 14 ago. 2020.

BRASIL. Lei $\mathbf{n}^{\circ}$ 7.287, de 18 de dezembro de 1984. Dispõe sobre a Regulamentação da Profissão de Museólogo. Disponível em: http://www.planalto.gov.br/ccivil_03/LEIS/L7287.htm\#: :text=LEI\%20No\%20 7.287\%2C\%20DE\%2018\%20DE\%20DEZEMBRO\%20DE\%201984.\&text=Disp\%C3\%B5e\%20sobre\%20 a\%20Regulamenta\%C3\%A7\%C3\%A30\%20da,O\%20PRESIDENTE\%20DA\%20REP\%C3\%9ABLICA\%3A\&text=IV\%20\%2D\%20dos\%20diplomados\%20em\%20outros,t\%C3\%A9cnicas\%20de\%20Museologia\%2C\%20devidamente\%20comprovados.. Acesso 14 ago. 2020.

BRASIL. Lei n 11.904, de 14 de janeiro de 2009. Institui o Estatuto de Museus e dá outras providências. Disponível em: http://www.planalto.gov.br/ccivil_03/_Ato2007-2010/2009/Lei/L11904.htm . Acesso 14 ago. 2020.

BRUNO, M. C. O. O ICOM- Brasil e o pensamento museológico brasileiro: documentos selecionados. São Paulo: Pinacoteca do Estado: Secretaria de Estado da Cultura: Comitê Brasileiro do ICOM. 2010. V.2. 402p.

DOHMANN, M. O objeto e a experiência material. Rio de Janeiro, Arte e Ensaios, v. 20, 2010.

ESTADO-MAIOR DO EXÉRCITO. Portaria nº52-EME, de 11 de Março de 2019. Estabelece as condições de funcionamento do Estágio Geral Interdisciplinar de Gestão Cultural para oficiais, subtenentes e sargentos. 2019a.

ESTADO-MAIOR DO EXÉRCITO. Portaria n 156-EME, de 08 de julho de 2020. Altera a Portaria $n^{\circ} 052-E M E$, de 11 de março de 2019, que estabelece as condições de funcionamento do Estágio-Geral Interdisciplinar de Gestão Cultural para oficiais, subtenentes e sargentos. 2020.

ESTADO-MAIOR DO EXÉRCITO. Portaria n 053-EME, de 11 de Março de 2019. Cria o Estágio Geral Interdisciplinar de Gestão Cultural para oficiais, subtenentes e sargentos. 2019b.

ESTADO-MAIOR DO EXÉRCITO. Portaria n 1.030, de 11 de outubro de 2013. Aprova as Instruções Gerais 
para a Criação, Denominação, Organização, Funcionamento, Preservação e Extinção de Espaços Culturais no âmbito do Exército Brasileiro (EB10-IG-01.009) e dá outras providências.

ICOM. Declaração de Caracas. 1992. Disponível em: http://www.ibermuseos.org/pt/recursos/documentos/declaracao-de-caracas-1992-2/. Acesso em 30/08/2020.

INSTITUTO BRASILEIRO DE GEOGRAFIA E ESTATÍSTICA. Sistema de informações e indicadores culturais 2003-2005. Rio de Janeiro: IBGE, 2007.

PLANO BÁSICO DE CULTURA DO EXÉRCITO BRASILEIRO, 2019-2020. Diretoria do Patrimônio Histórico e Cultural do Exército. Em aprovação.

PONCIANO, L. C. M. O; MACHADO, D. M. C.; CASTRO, A. R. S. F. Patrimônio Paleontológico. A Paleontologia na sala de aula, 2015. p.460-472.

RAFAEL, M. Políticas públicas para o campo museal: um estudo sobre o "programa de capacitação museológica" do sistema estadual de museus de Santa Catarina. 2017. 149 f. Dissertação (Mestrado) - Curso de Programa de Pós-Graduação Interunidades em Museologia, Universidade de São Paulo, São Paulo, 2017.

RUBIM, A. A. C.; BARBALHO, A. (Org.). Políticas culturais no Brasil. Salvador: EDUFBA, 2007.

SANTOS, M. C. T. M. Programa de Formação e Capacitação na Área de Museologia. 2003. Disponível em: http://www2.cultura.gov.br/site/wp-content/uploads/2007/09/programa-de-formacao-e-capacitacao-na-area-de-museologia.pdf . Acesso em 30/08/2020.

TOLENTINO, A. Programa de Formação e Capacitação em Museologia: oficinas de capacitação para profissionais de museus. In. Revista MUSAS, 2009. nº 4. p. 200-205. 